\title{
Nutritional status and energy expenditure in elderly patients with recent hip fracture during a 2-month follow-up
}

\author{
Elena Paillaud ${ }^{1}$, Phuong-Nhi Bories ${ }^{2}$, Jean-Claude Le Parco ${ }^{1}$ and Bernard Campillo ${ }^{3} *$ \\ ${ }^{1}$ Service de Médecine Interne, ${ }^{2}$ Laboratoire de Biochimie and ${ }^{3}$ Service de Rééducation Digestive, Hôpital Albert Chenevier, \\ Assistance Publique-Hôpitaux de Paris, 40 rue de Mesly, Créteil, France
}

(Received 10 December 1998 - Revised 19 July 1999 - Accepted 16 August 1999)

\begin{abstract}
A 2-month follow-up of nutritional status was performed in forty elderly patients with recent hip fracture. Patients were nutritionally assessed on admission to our rehabilitation unit (day 0), then monthly (day 30, day 60) by measurement of resting energy expenditure (REE), anthropometric, impedance and biological variables. Patients were defined as undernourished $(n 13)$ or normally nourished $(n$ 27) on the basis of mid-arm circumference (MAC) and triceps skinfold thickness (TST) measurements. Seven patients recovered a walking autonomy and were discharged from the hospital before day 30 (group I) whereas thirteen patients were discharged after day 30 (group II); twenty patients remained in the study at day 60 (group III). MAC and TST decreased in normally nourished patients from group III throughout the study whereas they did not change in group II or in undernourished patients from group III. REE values in relation to fat-free mass were increased compared with normal values and were similar in the three groups on day 0 ; they did not change during the study. Daily energy intake in relation to body weight was higher in group I and increased in group II and in undernourished patients from group III throughout the study. In contrast, it was below the recommended value at day 0 and it did not significantly improve in normally nourished patients from group III. Serum albumin, transthyretin and transferrin levels on day 0 were below reference intervals in the three groups. Albumin levels increased in group III throughout the study. Inflammatory proteins decreased in groups II and III, with C-reactive protein levels returning to normal values in group II by day 30 and in group III at day 60 , while orosomucoid levels did not become completely normal over this period. Our findings indicate no improvement in nutritional status in undernourished patients after surgery for recent hip fracture, despite an adequate energy intake. An insufficient spontaneous energy intake for normally nourished patients was associated with a delayed favourable outcome resulting in a prolonged duration of hospitalization. A hypermetabolic state persisted during the 3 months after surgery.
\end{abstract}

\section{Energy intake: Elderly: Hip fracture: Nutritional status}

Hip fracture in elderly people is of major concern in public health. It is associated with a high mortality rate and prolonged disability, and requires long-term medical care (Barrett-Connor, 1995). Malnutrition is often seen in the elderly and appears to be an important determinant of both incidence and complications of hip fracture in subjects with osteoporosis. Up to $58 \%$ of patients with acute fractured proximal femur are found to be undernourished at admission (Jensen et al. 1982; Patterson et al. 1992). Protein deficiency may contribute to the incidence of hip fracture by reducing muscle strength, diminishing the protective layer of soft tissue padding and accelerating the loss of bone mineral density at the proximal femur (Vellas et al. 1992; Bonjour et al. 1996). Protein malnutrition may also occur during recovery from surgery. In response to surgical stress, the patients have an inflammatory reaction: production of catabolic cytokines leads to increased energy expenditure, synthesis of acute-phase proteins and decreased food intake (Pomposelli et al. 1988). A long-lasting catabolic state may result in alteration in body composition, with severe muscle wasting. Thus, the imbalance between energy intake and energy expenditure may induce or exacerbate nutritional deficiencies, which are associated with decline in functional independence, and increased risk of postoperative complications and mortality (Delmi et al. 1990; Burness et al. 1996). These facts argue in favour of accurate evaluation of energy requirements and follow-up of the nutritional status in elderly patients with hip fracture. The

\footnotetext{
Abbreviations: CRP, C-reactive protein; MAC, mid-arm circumference; REE, resting energy expenditure; TST, triceps skinfold thickness; TT3, total triiodothyronine.

*Corresponding author: Dr Bernard Campillo, fax +33 1498130 13, email bernard-campillo@ach.ap-hop-paris.fr
} 
present study was carried out in order to follow the nutritional status in terms of anthropometric and impedance measures over a 2-month period in forty elderly patients with recent hip fracture. The adequacy of spontaneous food intake to meet energy requirement, as measured by indirect calorimetry, was examined. Biological variables relating to the nutritional and inflammatory status, and to the regulation of energy expenditure were measured.

\section{Methods \\ Patients}

Forty patients (five males and thirty-five females) aged between 70 and 91 years (mean age 84.0 (SE 1.9) years) entered this study. These patients were hospitalized between December 1996 and April 1998, for rehabilitation on average $21.8 \mathrm{~d}$ after surgery due to a hip fracture. Dementia, malignant tumour, uncontrolled heart or renal failure, thyroidal disease, and uncontrolled sepsis precluded participation in the study. All patients were informed of the purpose of the study and gave their consent.

Patients underwent rehabilitation on $5 \mathrm{~d}$ /week. The exercise sessions included an initially passive, then active movement of the affected leg for $10 \mathrm{~min}$, active working of the quadriceps for $10 \mathrm{~min}$, a walking activity with and later without assistance for $30 \mathrm{~min}$. The main criterion for hospital discharge was the recovery of a walking selfsufficiency.

\section{Study design}

Patients were nutritionally assessed on admission to our unit (day 0), then monthly (day 30, day 60) by measurement of resting energy expenditure (REE), anthropometric variables and impedance values. A blood sample was collected after an overnight fast on the same day as the nutritional assessment, for determination of serum proteins and thyroid hormones. Seven patients were discharged from hospital before day 30 (group I) whereas thirteen patients were discharged after day 30 (group II); twenty patients remained in the study at day 60 (group III) (Table 1). In addition, impedance analysis was performed in only twenty-nine patients on day 30 and REE was measured in only fifteen patients on day 60 .

\section{Anthropometric measurements}

Body weight, height estimated from tibia length (Chumlea et al. 1985), and BMI (weight/height ${ }^{2}$ ) were recorded. Midarm circumference (MAC) and triceps skinfold thickness
(TST) were as established according to the Anthropometric Standardization Manual (Lohman et al. 1988). TST was measured to the nearest mm using a Harpenden Caliper, and the average of three consecutive measurements was calculated. The patients were considered to be undernourished when MAC was $<23 \mathrm{~cm}$ and TST $<10 \mathrm{~mm}$ in women and $<6 \mathrm{~mm}$ in men (Table 1) (Ferry et al. 1996).

\section{Bioelectrical impedance analysis}

Bioelectrical impedance was measured after an overnight fast using an Analycor impedance analyser (Laboratoire Eugedia-Spengler, Cachan, France). Standard procedures were followed with the subject lying supine on a flat surface with the legs not touching at the thighs and the arms not touching the torso. Body impedance was measured with the same electrodes on the dorsal surfaces of the foot and hand, and the sensor electrodes between the lateral and medial malleoli of the ankle and between the distal prominences of the radius and ulna. Sentry electrodes (Sentry Medical Products Irvine, CA, USA) were used. The electrodes were then connected to the analyser and the resistance and reactance to the injection of a current of $800 \mu \mathrm{A}$ at 5, 50 and $100 \mathrm{kHz}$ were measured. Body composition was predicted by resistance measured respectively at 5,100 and $50 \mathrm{kHz}$ using Analycor software (Laboratoire Eugedia-Spengler) based on regression equations given by the manufacturer. Equations were derived from healthy subjects and incorporated weight and height in the calculation.

\section{Assessment of resting energy expenditure}

REE was calculated from gaseous exchange measurements using indirect calorimetry (Datex, Engstrom, Finland). Following an overnight fast, subjects were placed under a ventilated plexiglass hood and measurements of $\mathrm{O}_{2}$ consumption and $\mathrm{CO}_{2}$ production were taken every minute for a total of $30 \mathrm{~min}$ after a $5 \mathrm{~min}$ period of acclimatization. All subjects remained in bed in a quiet area of the ward throughout the study period. Measured REE was derived from the equation of de Weir (1949). Monthly calibration to check the flow rate and RQ was carried out by using an alcohol burning kit; variation between calibrations was $<2 \%$. The measured REE was compared with the predicted REE according to the equations of Harris \& Benedict (1919).

\section{Dietary intake}

The patients received the usual diet given in French hospitals, supplying on average $146-167 \mathrm{~kJ} / \mathrm{kg}$ per $\mathrm{d}$ with

Table 1. Characteristics of the patient population

\begin{tabular}{|c|c|c|c|c|c|c|}
\hline & \multirow{2}{*}{$\begin{array}{l}\text { Duration of participation } \\
\text { in the study }\end{array}$} & \multicolumn{2}{|c|}{ Age (years) } & \multirow[b]{2}{*}{$\mathrm{M} / \mathrm{F}$} & \multirow[b]{2}{*}{ Undernourished } & \multirow{2}{*}{$\begin{array}{l}\text { Normally } \\
\text { nourished }\end{array}$} \\
\hline & & Mean & SEM & & & \\
\hline Group I (n 7) & $<1$ month & $84 \cdot 3$ & 3.6 & $2 / 5$ & 2 & 5 \\
\hline Group II ( $n$ 13) & 1 month & 81.5 & 1.9 & $1 / 12$ & 3 & 10 \\
\hline Group III ( $n$ 20) & 2 months & $86 \cdot 4$ & 0.9 & $2 / 18$ & 8 & 12 \\
\hline
\end{tabular}

M, males; F, females. 
Table 2. Anthropometric variables and impedance values in three groups of elderly patients* who had undergone surgery for hip fracture (Mean values with their standard errors)

\begin{tabular}{|c|c|c|c|c|c|c|c|c|c|c|c|c|c|c|}
\hline & \multicolumn{2}{|c|}{ Weight (kg) } & \multicolumn{2}{|c|}{ BMI $\left(\mathrm{kg} / \mathrm{m}^{2}\right)$} & \multicolumn{2}{|c|}{ FFM (kg) } & \multicolumn{2}{|c|}{$\mathrm{BCM}(\mathrm{kg})$} & \multicolumn{2}{|c|}{$\mathrm{FM}(\mathrm{kg})$} & \multicolumn{2}{|c|}{ TST (mm) } & \multicolumn{2}{|c|}{ MAC (cm) } \\
\hline & Mean & SEM & Mean & SEM & Mean & SEM & Mean & SEM & Mean & SEM & Mean & SEM & Mean & SEM \\
\hline \multicolumn{15}{|c|}{ Group I (n 7) } \\
\hline Day 0 & $52 \cdot 8$ & $6 \cdot 5$ & $21 \cdot 1$ & $2 \cdot 1$ & 34.9 & 3.5 & $22 \cdot 0$ & $2 \cdot 8$ & $17 \cdot 9$ & 3.6 & 11.9 & $2 \cdot 0$ & $25 \cdot 1$ & $2 \cdot 3$ \\
\hline \multicolumn{15}{|c|}{ Group II ( $n$ 13) } \\
\hline Day 0 & $52 \cdot 8$ & $2 \cdot 7$ & 21.5 & 1.2 & 33.6 & 1.4 & 21.1 & 1.1 & $19 \cdot 3$ & 1.8 & $12 \cdot 3$ & 1.9 & 24.7 & 1.2 \\
\hline Day 30 & $52 \cdot 4$ & 3.0 & $21 \cdot 4$ & 1.4 & $33 \cdot 1$ & $1 \cdot 2$ & 21.6 & $1 \cdot 1$ & $19 \cdot 3$ & $2 \cdot 4$ & 11.9 & $2 \cdot 0$ & 24.0 & 1.3 \\
\hline \multicolumn{15}{|c|}{ Group III (n 20) } \\
\hline Day 0 & $50 \cdot 8$ & $3 \cdot 1$ & $22 \cdot 2$ & $1 \cdot 1$ & 32.9 & 1.5 & 20.5 & 1.2 & $18 \cdot 1$ & $2 \cdot 0$ & 11.0 & 1.4 & $24 \cdot 1$ & 0.9 \\
\hline Day 30 & $48 \cdot 1$ & $2 \cdot 8$ & $21 \cdot 1$ & 1.0 & $31 \cdot 6$ & $1 \cdot 3$ & $19 \cdot 4$ & 1.0 & $16 \cdot 4$ & $2 \cdot 0$ & 9.4 & 1.2 & 23.5 & $0 \cdot 8$ \\
\hline Day 60 & $50 \cdot 1$ & 3.0 & $21 \cdot 6$ & $1 \cdot 1$ & 32.9 & 1.4 & $20 \cdot 4$ & $1 \cdot 1$ & $17 \cdot 2$ & $2 \cdot 0$ & $9 \cdot 7$ & $1 \cdot 1$ & 23.9 & 0.8 \\
\hline
\end{tabular}

FFM, fat-free mass; BCM, body cell mass; FM, fat mass; TST, triceps skinfold thickness; MAC, mid-arm circumference.

${ }^{*}$ For details of groups, see Table 1.

proportions of carbohydrate, lipid and protein respectively of 55,30 and $15 \%$ energy. The diet was conventional, nutrients and fluids were given orally. The energy and protein intakes were recorded by a dietitian immediately after each meal. The composition of the diet was determined from tables (Ostrowski, 1978). Data are given as the means of five consecutive $24 \mathrm{~h}$ intakes at each time point.

\section{Biological measurements}

Serum transthyretin, transferrin, C-reactive protein (CRP) and orosomucoid concentrations were analysed immunoturbidimetrically on a Synchron CX5 analyser (BeckmanCoulter, Roissy, France). Serum albumin concentration was measured by means of the bromocresol green method with the Synchron CX5 analyser. The thyroid hormones total triiodothyronine (TT3), free thyroxine and thyroidstimulating hormone were analysed by means of a chemiluminescent assay on a Magic-lite 2 analyser (Chiron-Diagnostics, Cergy Pontoise, France). For each patient, the blood samples collected on days 0, 30 and 60 were assayed in the same run. The intra-assay CV were
$3-4 \%$ for proteins and $4-7 \%$ for thyroid hormones. The inter-assay $\mathrm{CV}$ were respectively $4-6 \%$ and 6-9\%.

\section{Statistical analysis}

The results are expressed as means with their standard errors. Biological data and some of the anthropometric variables were interpreted in the light of reference values previously established in our laboratory for healthy elderly people (Cals et al. 1994). Two groups of patients were compared using the unpaired $t$-test or the $\chi^{2}$ test, as appropriate. The one-way ANOVA with repeated measures was used for group III to study changes in a variable over time. The paired Student's $t$ test or the Wilcoxon test was used for comparison of data at day 0 and day 30 as appropriate. Correlations between two variables were calculated with least squares regression analysis. A $5 \%$ significance level was used in all comparisons.

\section{Results}

In our study population, thirteen patients, all women, were found to be undernourished (BMI 17.0 (SE 0.7) kg/m²; MAC

Table 3. Values for resting energy expenditure (REE) and energy intake (EI) in three groups of elderly subjectsł who had undergone surgery for hip fracture

(Mean values with their standard errors)

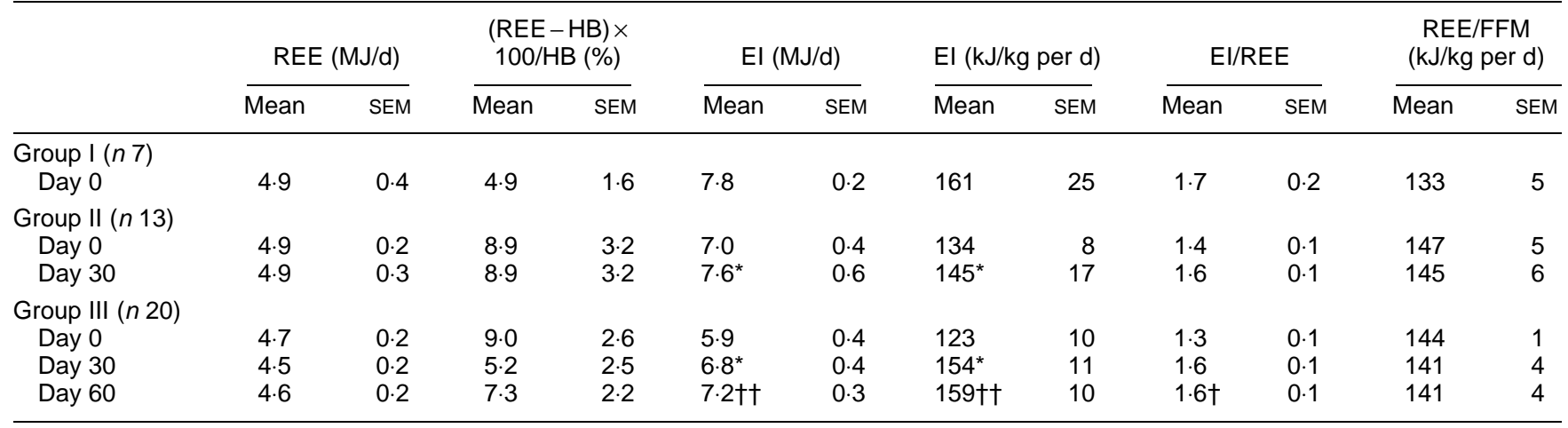

HB, REE measured by the equation of Harris \& Benedict (1919); FFM, fat-free mass.

Mean values were significantly different from those for day $0:{ }^{*} P<0.05$ (paired Student's $t$ test).

Mean values within group III differed significantly over time: $\dagger P<0.02$, $† \dagger P<0.01$ (repeated measures ANOVA).

$\ddagger$ For details of groups, see Table 1. 
19.5 (SE 0.7) cm; TST 5.6 (SE 0.8) mm) while twenty-seven patients, including five men and twenty-two women, were normally nourished (BMI 24.3 (SE 0.7 ) $\mathrm{kg} / \mathrm{m}^{2}$; MAC 27.0 (SE 0.5) cm; TST 14.5 (SE 1.0) mm). BMI and MAC values observed in the latter were very close to those described for healthy, free-living elderly subjects (Cals et al. 1994). The undernourished patients had a shorter delay between surgery and entry to the study (19.2 (SE 1.3) v. 23.4 (SE 1.2) d; $P=$ 0.033 ). There was an apparent, although not significant, higher risk of complications: $46 \%$ for the undernourished $v$. $22 \%$ for the normally nourished. Complications in the former patients were urinary tract infection $(n 2)$, pressure sore, acute bronchitis, depressive syndrome and acute cardiac arrhythmia while those in the latter were urinary tract infection ( $n 2)$, pressure sore, acute diarrhoea and bacteraemia. Among the normally nourished patients, five achieved a good clinical outcome and walking autonomy before day 30 while ten other patients could also be discharged from the hospital after day 30; therefore only $44 \%$ completed the trial (Table 1). On the other hand, among the undernourished patients, two dropped out before day 30 while eight patients $(62 \%)$ still remained in the study at day 60 (Table 1).

Three groups of patients were defined according to duration of hospitalization. Group I ( $n$ 7) was composed of patients who were discharged before day 30, group II ( $n$ 13) included patients who were discharged after day 30 but before day 60. Patients who completed the trial were in group III ( $n$ 20). The three groups did not differ in terms of proportion of malnourished patients, sex distribution and age.

Anthropometric and impedance values were in the same range in the three groups of patients (Table 2). No significant change could be observed for any variable over the study period, except for MAC and TST which decreased in normally nourished patients from group III (see Table 5).

The Harris \& Benedict (1919) equations underestimated the measured REE by less than $10 \%$ (Table 3 ). On entry into the study, REE values were similar in the three groups; they were higher than those previously observed in nonsurgical elderly patients (Campillo et al. 1992). The REE remained stable in groups II and III throughout the study (Table 3). Daily food intake at day 0 was higher in patient group I than in group III $(P=0 \cdot 0043)$. A significant increase in energy intake was observed in groups II and III over the study period and was confirmed by similar changes in energy intake related to body weight or to REE (Table 3). However, when taking into account the nutritional status of the patients in group III, the increase in energy intake remained significant only in undernourished patients (see Table 5).

Biological data are presented in Table 4. Mean albumin and transferrin levels on day 0 in all groups were below the reference values defined for healthy elderly people (respectively $36-45 \mathrm{~g} / \mathrm{l}$ and $2 \cdot 20-3.60 \mathrm{~g} / \mathrm{l}$; Cals et al, 1994), whereas transthyretin levels were at the lower limit of the reference range $(0 \cdot 19-0 \cdot 35 \mathrm{~g} / \mathrm{l})$. However, mean albumin level on day 0 was higher in group II than in group III $(P=$ 0.0178). It increased in the latter throughout the study (Table 4), more particularly in the normally nourished patients with return to levels within the reference interval by day $30 \quad(P=0.0025$; Table 5$)$. Transthyretin and

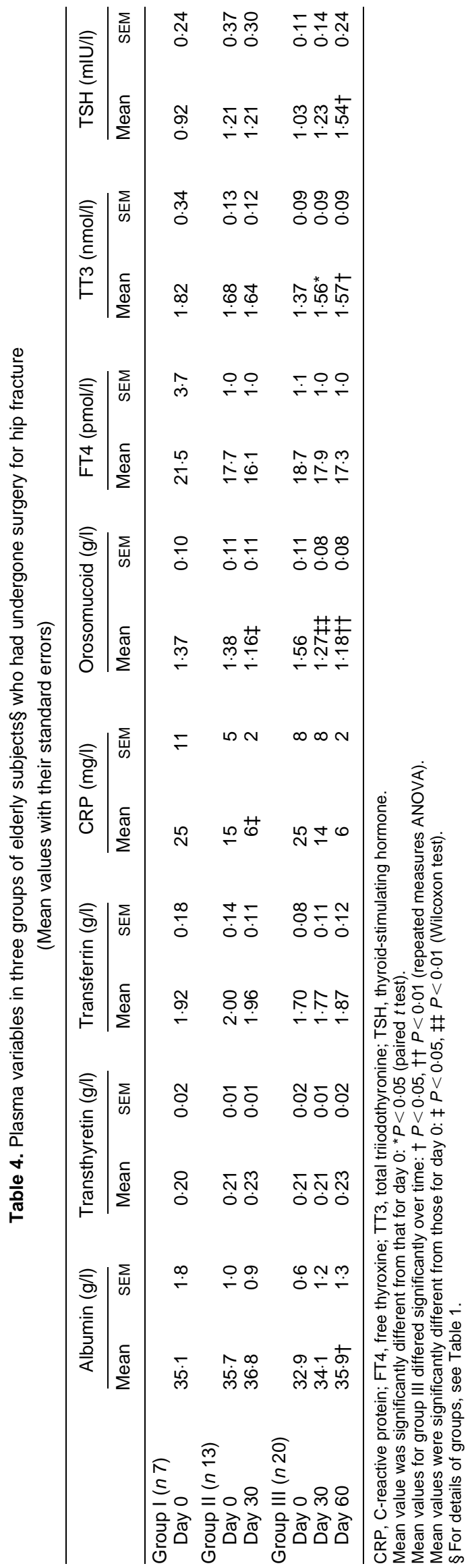


transferrin levels did not change significantly for the duration of the study.

CRP and orosomucoid levels on day 0 were above the reference range (CRP $<6 \mathrm{mg} / \mathrm{l}$; orosomucoid $0.50-1.16 \mathrm{~g} / \mathrm{l})$ in all groups (Table 4). Orosomucoid decreased throughout the study in patients from groups II and III (Table 4), particularly in normally nourished patients (Table 5). CRP levels fell gradually to normal values by the end of the first month of the study in group II and in normally nourished patients from group III (Tables 4 and 5). Changes in these two inflammatory proteins between day 0 and day 30 were highly correlated one with another $(r 0.750, P<0.0001)$.

Free thyroxine and thyroid-stimulating hormone levels were within the normal range on entry into the study (respectively $10.0-23.0 \mathrm{pmol} / \mathrm{l}$ and $0.25-5.00 \mathrm{mIU} / \mathrm{l}$ ) and did not differ among the three groups (Table 4). In contrast, the mean TT3 level was below the limit of the normal range $(1.50-3.00 \mathrm{nmol} / \mathrm{l})$ in patient group III. Thyroid-stimulating hormone and TT3 levels increased in this group throughout the study (Table 4). However, TT3 still remained below the normal limits in undernourished patients while it returned to values within the normal range in normally nourished patients (Table 5). In addition, a negative correlation was observed in the whole population between changes in TT3 and those in orosomucoid $(r-0.579, P=0.0004)$ and CRP $(r-0.622, P=0.0004)$.

\section{Discussion}

In our present study, $87 \%$ of the patients enrolled were women; this reflects the higher incidence of hip fracture in this population (Barrett-Connor, 1995). Of the patients $33 \%$ were found to be undernourished $20 \mathrm{~d}$ after hip-fracture surgery. This rate of malnutrition is slightly lower than that reported in the literature (58\%) (Jensen et al. 1982; Patterson et al 1992). Our exclusion criteria, e.g. uncontrolled acute disease, may have caused the rate of malnutrition recorded in our patients to be slightly less than that commonly encountered in this type of patient. It should be noted that among those patients who did not enter the study, five died a few days after admission to our department.

Values for REE in relation to fat-free mass were comparable in the three groups of patients. These values were close to those which we had measured previously in elderly patients, 1-6 months after surgery (141.0 (SE 4.6) $\mathrm{kJ} / \mathrm{kg}$ per d). However, REE/fat-free mass values from our patients were dramatically higher than those reported for nonsurgical elderly patients in a stable clinical condition (125.0 (SE 5.9) kJ/kg per d; Campillo et al. 1992) as well as for healthy elderly subjects $(117.2 \mathrm{~kJ} / \mathrm{kg}$ per d; Vaughan et al. 1991; Roberts et al. 1992; Poehlman, 1996; Reilly et al. 1996). These results suggest that our patient population remained in an increased metabolic state throughout the study and are concordant with results of other studies showing significant effects of trauma and surgery on REE (Patterson et al. 1992; Nelson et al. 1995). Nevertheless, the existence of hypermetabolism in our patients was not confirmed by predicted REE values according to the equations of Harris \& Benedict (1919), which were only about $10 \%$ lower than the measured ones. A similar discordance was observed by Jallut et al. (1990) in elderly patients with 
hip fracture, $3 \mathrm{~d}$ after the surgical operation, although REE values were significantly higher than those measured 5-6d later. Overall, these findings suggest that Harris \& Benedict's (1919) equations cannot be applied to elderly patients with multiple diseases.

The oral diet given to our patients provided $8.37 \mathrm{MJ} / \mathrm{d}$ ( $2000 \mathrm{kcal} / \mathrm{d})$; however on entry into the study, only $75 \%$ was really ingested. Energy intake in relation to body weight appeared to be adequate for patients from groups I and II who achieved the earliest recovery, since it was above that recommended by WHO for healthy sedentary elderly women $(7.95 \mathrm{MJ} / \mathrm{d}(1900 \mathrm{kcal} / \mathrm{d})$ or $134 \mathrm{~kJ} / \mathrm{kg}$ per $\mathrm{d}$ (32 kcal/kg per d) World Health Organization, 1986). Nutrient requirements were also met for undernourished patients from group III; however, the benefit in terms of nutritional and biochemical course was not apparent by day 60 . In contrast, spontaneous oral intake by the normally nourished patients from group III $(112 \mathrm{~kJ} / \mathrm{kg}$ per d) was initially insufficient; furthermore they showed increased BMR values. Intake increased non-significantly throughout the study but was still below the recommended value for half the group by day 60 . This might have contributed to decreased MAC and TST values in these patients, contrasting with an upward trend of MAC in the undernourished patients.

At 3 weeks post-surgery, a moderate inflammatory state still remained in our patients, as shown by slightly increased values for CRP and orosomucoid concomitant with low levels of albumin, transthyretin and transferrin. Improvement of inflammatory syndrome was obvious in patients who were discharged from the hospital by day 30 . For those who had to be hospitalized for a longer time, the decrease in inflammatory proteins occurred earlier in normally nourished patients and was concomitant with an increase in albumin levels. Nevertheless, albumin levels in these patients were unexpectedly at the lower limit of our reference interval on day 60, although their nutritional status was good and comparable to that in healthy elderly subjects, in terms of BMI and MAC. One possible explanation may be given by orosomucoid levels which did not become fully normal until almost 3 months post-surgery; this suggests a persistent mild inflammatory syndrome which may have contributed to the increased metabolic rate in our patients. Second, the borderline value of serum albumin was in agreement with decreased MAC and TST in this subgroup, as mentioned earlier. Therefore, we cannot exclude the possibility that insufficient energy intake led to an alteration of nutritional status in these patients.

Regarding thyroid hormone status, TT3 levels were below the reference interval in patient group III and increased throughout the study, contrasting with a downward trend of free-thyroxine levels; moreover, changes in TT3 correlated with those in orosomucoid and CRP in the whole population. The so-called low triiodothyronine syndrome during illness has already been described by several authors (Danforth \& Burger, 1989; Szabolcs et al. 1993; Goichot et al. 1994) and its pathogenesis has been hypothesized to involve cytokines (Boelen et al. 1993, 1995; Allegra et al. 1998). In view of these reports, our data suggest that the reduction of the inflammatory syndrome seen in our patients led to an increased rate of conversion of thyroxine to triiodothyronine. These modifications in thyroid hormone metabolism may represent an adaptive mechanism aimed at reducing metabolic demands due to stress.

In conclusion, the present study showed no improvement in nutritional status in recently hip-fractured elderly patients who needed a 3-month rehabilitation period. This may have resulted from a hypermetabolic state promoted by a residual inflammatory syndrome. It should be noted that nutrient intake, although adapted to energy requirements, could not improve nutritional status in undernourished patients. In contrast, an inadequate energy intake for normally nourished patients was associated with a longer rehabilitation period and a trend toward an altered anthropometric course. Finally, the inflammatory syndrome was associated with modifications in thyroid hormone metabolism. Our findings may lead to a better understanding of energy metabolism in stressed elderly patients and may provide a rational basis for an appropriate nutritional intervention in these patients.

\section{References}

Allegra A, Corica F, Buemi M, Corsonello A, Rubino F, Raffaele Addamo F, Bonanzinga S, Nicita Mauro V \& Ceruso D (1998) Plasma interleukin-2 levels and thyroid function in elderly patients with nonthyroidal illness. Archives of Gerontology and Geriatrics 26, 275-282.

Barrett-Connor E (1995) The economic and human costs of osteoporotic fracture. American Journal of Medicine 98, Suppl. $2 \mathrm{~A}, 3 \mathrm{~S}-8 \mathrm{~S}$.

Boelen A, Platvoet-Ter Schiphorst MC \& Wiersinga WM (1993) Association between serum interleukin-6 and serum 3,5,3'triiodothyronine in non thyroidal illness. Journal of Clinical Endocrinology and Metabolism 77, 1695-1699.

Boelen A, Platvoet-Ter Schiphorst MC \& Wiersinga WM (1995) Soluble cytokine receptors and the low 3,5,3'-triiodothyronine syndrome in patients with nonthyroidal disease. Journal of Clinical Endocrinology and Metabolism 80, 971-976.

Bonjour JP, Schurch MA \& Rizzoli R (1996) Nutritional aspects of hip fracture. Bone 18, 139S-144S.

Burness R, Horne G \& Purdie G (1996) Albumin levels and mortality in patients with hip fractures. New Zealand Medical Journal 109, 56-57.

Cals MJ, Bories PN, Devanlay M, Desveaux N, Luciani L, Succari M, Duche JC, de Jaeger C, Blonde-Cynober F \& Coudray-Lucas C (1994) Extensive laboratory assessment of nutritional status in fit, health-conscious, elderly people living in the Paris area. Journal of the American College of Nutrition 13, 646-657.

Campillo B, Bories PN, Devanlay M, Pornin B, Le Parco JC, GayeBareyt E \& Fouet P (1992) Aging, energy expenditure and nutritional status: evidence for denutrition-related hypermetabolism. Annals of Nutrition and Metabolism 36, 265-272.

Chumlea WC, Roche AF \& Steinbaugh ML (1985) Estimating stature from knee height for persons 60 to 90 years of age. Journal of the American Geriatrics Society 33, 116-120.

Danforth E \& Burger AG (1989) The impact of nutrition on thyroid hormone physiology and action. Annual Review of Nutrition 9 , 201-227.

de Weir JBV (1949) New methods for calculating metabolic rate with special reference to protein metabolism. Journal of Physiology 109, 1-9.

Delmi M, Rapin CH, Bengoa JM, Delmas PD, Vasey H \& Bonjour JP (1990) Dietary supplementation in elderly patients with fractured neck of the femur. Lancet 335, 1013-1016. 
Ferry M, Alix E, Brocker P, Constans T, Lesourd B \& Vellas B (1996) Epidemiology of malnutrition. In Nutrition de la Personne Agée [M Ferry, editor]. Paris: Berger-Levrault.

Goichot B, Schlienger JL, Grunenberger F, Pradignac A \& Sapin R (1994) Thyroid hormone status and nutrient intake in free-living elderly. Interest of reverse triiodothyronine assessment. European Journal of Endocrinology 130, 244-252.

Harris JA \& Benedict FG (1919) A Biometric Study of Basal Metabolism in Man. Carnegie Institute of Washington Publication no. 279. Washington, DC: Carnegie Institute.

Jallut D, Tappy L, Kohut M, Bloesch D, Munger R, Schutz Y, Chiolero R, Felber JP, Livio JJ \& Jequier E (1990) Energy balance in elderly patients after surgery for a femoral neck fracture. Journal of Parenteral and Enteral Nutrition 14, 563568.

Jensen JE, Jensen TG, Smith TK, Johnston DA \& Dudrick SJ (1982) Nutrition in orthopaedic surgery. Journal of Bone and Joint Surgery 64A, 1263-1272.

Lohman TG, Roche AF \& Martorell R (1988) Anthropometric Standardization Manual. Illinois: Human Kinetic Books.

Nelson KM, Richards EW, Long CL, Martin KR, Geiger JW, Brooks SW, Gandy RE \& Blakemore WS (1995) Protein and energy balance following femoral neck fracture in geriatric patients. Metabolism 44, 59-66.

Ostrowski ZL (editor) (1978) Nutrients. Food Composition Tables. Paris: J. Lanore.

Patterson BM, Cornell CN, Carbone B, Levine B \& Chapman D
(1992) Protein depletion and metabolic stress in elderly patients who have a fracture of the hip. Journal of Bone and Joint Surgery 74A, 251-260.

Poehlman E (1996) Energy intake and energy expenditure in the elderly. American Journal of Human Biology 8, 199-206.

Pomposelli JJ, Flores EA \& Bistrian BR (1988) Role of biochemical mediators in clinical nutrition and surgical metabolism. Journal of Parenteral and Enteral Nutrition 12, 212-218.

Reilly JJ, Lord A, Bunker VW, Prentice AM, Coward WA, Thomas AJ \& Briggs RS (1993) Energy balance in healthy elderly women. British Journal of Nutrition 69, 21-27.

Roberts SB, Young VR, Fuss P, Heyman MB, Fiatarone M, Dallal GE, Cortiella J \& Evans WJ (1992) What are the dietary energy needs of elderly adults? International Journal of Obesity 16, 969-976.

Szabolcs I, Ploenes C, Beyer M, Bernard W \& Herrmann J (1993) Factors affecting the serum free thyroxine levels in hospitalized chronic geriatric patients. Journal of the American Geriatrics Society 41, 742-746.

Vaughan L, Zurlo F \& Ravussin E (1991) Aging and energy expenditure. American Journal of Clinical Nutrition 53, 821825 .

Vellas B, Baumgartner RN, Wayne SJ, Conceicao J, Lafont C, Albarede JL \& Garry PJ (1992) Relationship between malnutrition and falls in the elderly. Nutrition 8, 105-108.

World Health Organization (1986) Energy and Protein Requirements. Technical Report Series no. 724. Geneva: WHO. 